\title{
FORMAÇÃO ARTÍSTICA: UM ESPAÇO NÃO FORMAL PARA DISCUTIR EDUCAÇÃO AMBIENTAL E CIDADANIA EM TEIXEIRA DE FREITAS (BA)
}

Hadassa Marques Santana Carmo ${ }^{1}$ Ana Odália Vieira Sena ${ }^{2}$ Alexsandro Santos da Silva ${ }^{3}$

Resumo: A arte e a ciência são campos cujas pontes se estabelecem ao longo da história. Tais aproximações se constituem para buscar a compreensão sobre o universo e suas múltiplas alterações, pois "artistas e cientistas percebem o mundo da mesma forma, apenas representam-no com linguagens diferentes" (REIS; GUERRA; BRAGA, 2006, p. 72). Partindo dessa compreensão, pensar sobre o mundo e as ações antrópicas sobre a natureza são temáticas presentes nas diversas expressões artísticas, bem como, nas discussões da Educação Ambiental (EA), deixando assim o campo do discurso e passando a ser um lugar de ações em espaços não formais de ensino. Por isso, a presente pesquisa buscou responder: qual a relação que se estabelece entre a arte e as questões socioambientais no contexto da Agnaldo Bomfim Escola de Dança em Teixeira de Freitas (BA)? A pesquisa foi realizada com cinco integrantes do curso (duas mulheres e três homens) e o professor, que responderam a um questionário. Este trabalho foi analisado a partir da Análise Textual Discursiva - ATD (MORAES, GALIAZZI, 2006), cujo resultado permitiu a constituição de dois metatextos: "A dança como espaço de mudança pessoal, social e ambiental" e "Criação e reflexão, atos de mão dupla na arte". Esperamos que esta pesquisa possa contribuir com o campo de Educação Ambiental e possibilite ampliar a compreensão de como a arte pode ser instrumento social de reflexão sobre questões socioambientais.

Palavras-chave: Educação Ambiental; Arte; Espaço Não Escolar.

1 Universidade do Estado da Bahia.Email:hdscarmo@gmail.com. http://lattes.cnpq.br/2619385825481217 2Universidade do Estado da Bahia. Email:odaliasena@gmail.com. http://lattes.cnpq.br/3502748511859086

3 Universidade do Estado da Bahia.Email:lex-1alex@hotmail.com. http://lattes.cnpq.br/0350657462734060 
Abstract: Art and science are fields whose bridges have been established throughout history. Such approaches are constituted to seek understanding about the universe and its multiple changes, because "artists and scientists perceive the world in the same way, they only represent it with different languages" (REIS; GUERRA; BRAGA, 2006, p.72). Based on this understanding, thinking about the world and anthropic actions on nature are themes present in the various artistic expressions, as well as in the discussions of Environmental Education (EE), thus ceasing to be a niche of speeches and becoming a place for actions in non-formal teaching spaces. Therefore, this research sought to answer: what is the relationship established between art and socio- environmental issues in the context of Agnaldo Bomfim Escola de Dança in Teixeira de Freitas (BA, Brazil)? The survey was carried out with five members of the course (two women and three men) and the teacher who answered a questionnaire. The work was analyzed from the Discursive Textual Analysis - ATD (MORAES, GALIAZZI, 2006), whose result allowed the constitution of two metatexts; "Dance as a space for personal, social and environmental change" and "Creation and reflection, two-way acts in art". We hope that this research can contribute to the field of Environmental Education and make it possible to broaden the understanding of how art can be a social instrument for reflection on socio-environmental issues.

Keywords: Environmental Education; Art; Non-School Space.

\author{
ATO \\ Mato que cresce teimoso. \\ Ato de resiliência! \\ Mesmo quando ao lado, \\ Tudo sufoca a existência. [...]
}

\title{
Introdução
}

\section{Abram as cortinas}

Qual a importância de se pensar... Por que não jogar lixo no chão, mas na lixeira? O que é lixo? Lixo ou resíduo sólido? Qual o destino dos resíduos? Uma criança de sete anos questionando o porquê de tudo? Não. Essa deveria ser a postura de todo cidadão ecologicamente consciente.

A responsabilidade pelo que consumimos e o seu destino final precisam fundamentar as ações cotidianas de cada um, pois um ato aparentemente simples não é. O agir precisa ser algo que "integre a economia, a sociedade e o meio ambiente, resultando em melhores relações do homem com o ambiente, e consequentemente na melhoria de sua qualidade de vida" (KONDRAT; MACIEL, 2013, p. 826).

Alcançar essa reflexão constante não é uma tarefa fácil, por isso, a 
conhecimento. Mas, como afirma Cachapuz (2014), um conhecimento que vá mais além da segmentação e hierarquização dos saberes. Um conhecimento que gere incômodo, reflexão e propicie uma construção gradual de mudanças no agir cotidiano.

Degasperi e Bonotto (2017) ressaltam que essa construção do pensar ecologicamente precisa estar inserida no processo da constituição dos sujeitos, que, por vezes, apropriam-se inconscientemente dos valores construídos na sociedade, como, por exemplo, o consumo excessivo para alcançar a felicidade. Contudo, essa apropriação não é precedida da necessária reflexão, ou de uma autoanálise relativa às motivações que orientam suas escolhas, por isso, a importância da Educação Ambiental em diferentes espaços, seja ele formal ou não formal.

Nos espaços não formais de aprendizagem existe uma liberdade de interação, pois "o grande educador é o 'outro', aquele com quem interagimos ou nos integramos" (GOHN, 2006, p. 29). Logo, pensar sobre EA nesses espaços pode agigantar-se, pois entre pares, a construção do conhecimento ecologicamente sustentável se torna mais reflexiva. Tal processo quando realizado através da arte propicia, além da problematização interna nos espaços não formais, a extensão para o público que interage com as obras. Assim, o artista provoca o imagético, a fim de expressar aspectos do cotidiano trazendo para sua obra o ato de denunciar, comunicar e instigar o pensamento, construindo rupturas em relação a uma visão de mundo aceita pelo senso comum, segundo Canda (2010).

Nesse contexto é importante olhar para a construção de valores socioambientais nesses espaços. Por isso, esta pesquisa tem como foco de estudo um projeto de formação artística para jovens em Teixeira de Freitas que tem produzido espetáculos de dança que discutem o respeito ao meio ambiente e a condição humana. Para tal, partimos da seguinte pergunta: qual a relação que se estabelece entre a arte e as questões socioambientais no contexto da Agnaldo Bomfim Escola de Dança em Teixeira de Freitas-BA?

O artigo foi organizado seguindo o encadeamento de um ballet de repertório e inspirado na elaboração do artigo de Freitas e Gonçalves (2018).

\author{
[...]Mato sempre que abafo, \\ Em mim, o ato de cuidado. \\ Entre resíduos e mais resíduos \\ Nasce uma frase... Um slogan: \\ Consumo consciente! \\ Hilário! \\ Icônico! \\ Algo antagônico? \\ Um ar fresco no eu consumidor. [...]
}




\section{ATO I: Um percurso entre teorias e novas teorias}

A arte e a ciência são campos cujas pontes se estabelecem ao longo da história. Tais interações se formam pois, tanto na arte como na ciência, suas criações se constituem através de narrativas, tornando assim possível refletir confluências e similaridades "sem prejuízo do reconhecimento de quais são ou podem ser as peculiaridades e as especificidades das linguagens, figuras e outros elementos de cada forma de conhecimento, esclarecimento ou deslumbramento" (IANNI, 2004, p. 10).

Tais aproximações se compõem para buscar a compreensão sobre o universo e suas múltiplas alterações, pois "artistas e cientistas percebem o mundo da mesma forma, apenas representam-no com linguagens diferentes" (REIS; GUERRA; BRAGA, 2006, p. 72). Essa compatibilidade de interesses permite que em cada campo, seja na arte ou na ciência, haja "[...] espaços de possibilidades, investigação, autoria, autonomia, construção de conhecimentos e subjetividade", como afirma Klisys (2010, p. 13).

A ciência, quando artisticamente representada, pode agigantar-se, pois une o racional e o emocional provocando assim múltiplas interações no ser e permite assim "tocar o sujeito, no sentido de que ele possa refletir e se posicionar sobre questões cotidianas e científicas relevantes para a sociedade em que vive", como afirmam Freitas e Gonçalves (2018, p. 201). A partir dessas percepções, compreendemos que a arte é um espaço reflexivo e crítico para se discutir a ciência e a sociedade proporcionando que o indivíduo possa ter uma formação ativa e cidadã.

A arte, quando discute temas científicos e relevantes para compreensão do mundo, proporciona uma ruptura com a memorização e o processo de aprendizagem se torna mais coerente para o grupo que a constrói e que a vê/sente. Para Degasperi e Bonotto (2017, p. 629), a articulação "afetivo-cognitiva pode nos encaminhar à ação consciente, intencional, visando à construção de relações que privilegiem a alteridade e o outro, dando voz ao que foi objetificado e construindo, assim, novos sentidos para a relação sociedade-natureza", alcançando uma formação integral.

Nessa relação arte e ciência, as explicações dos fenômenos tornam-se mais acessíveis, ao público em geral, permitindo que pessoas com níveis educacionais diferentes possam se apropriar dos conceitos, a partir das suas percepções sensoriais. Os autores Reis, Guerra e Braga (2006, p. 84) afirmam que fazendo "uma abordagem cultural da ciência esta poderá nos ajudar a compreendê-la melhor", constituindo uma apreensão não apenas científica, mas também humana e social.

A partir da associação desses campos, vistos como dicotômicos, racional/emocional, o conhecimento se constitui numa interface que "vá mais além da segmentação e hierarquização dos saberes" (CACHAPUZ, 2014, p, 96). Rompendo com o pensamento positivista da sobreposição de saberes e passando a entender a construção do conhecimento como "resultado de 
produções sociais repletas de sentido para o entendimento sobre a vida, bem como, para a criação de instrumentos e ferramentas para a atuação do sujeito e do seu estar-no-mundo" (CANDA, 2010, p. 251). Deixando de ser um processo mecânico e unidirecional, passando a ser algo dinâmico e construtivo.

Dentro desse cenário, a temática "mundo e as ações antrópicas sobre a natureza" está presente nas diversas expressões artísticas, bem como nas discussões da Educação Ambiental (EA), deixando assim de ser um espaço de falas e passando a ser um lugar de expressões e ações que tocam de maneira racional e emocional o seu receptor.

Partimos da compreensão que a EA se constitui por processos pelos quais o "indivíduo e a coletividade constroem valores sociais, conhecimentos, habilidades, atitudes e competências voltadas para a conservação do meio ambiente" (BRASIL, 1999). E para alcançar tal percepção, Carvalho (2006) afirma que existem três dimensões: os conhecimentos, os valores (éticos e estéticos) e a participação política do indivíduo, estando estas imbricadas umas nas outras. Corroborando essas ideias, Degasperi e Bonotto (2017, p. 626) afirmam que tais dimensões "são inerentes às práticas humanas e devem interagir, constantemente, visando à formação de sujeitos emancipados, críticos, comprometidos com a ação no mundo", formando assim uma visão reflexiva e cidadã sobre o meio ambiente.

Nesse sentido, Gomes e Nakayama (2017, p. 258) discutem que é preciso estimular o "exercício pleno da cidadania em um processo de conscientização (consciência + ação) para exteriorizar em ações aquilo que interiorizamos (razão e emoção) para uma reflexão crítica". Dessa maneira, a conscientização não surge apenas no que diz respeito aos conhecimentos dos conceitos ecológicos e processos científicos a eles relacionados, mas também enquanto a formação de sua cidadania. Entendemos, assim como Domingues (2017), que a cidadania é a participação dos indivíduos de uma determinada comunidade que busca de maneira ativa a igualdade em todos os campos que compõem a realidade humana, seja ela econômica, social ou ambiental.

$E$ essa formação cidadã em relação ao meio ambiente que leva a pensar e agir sobre ações que mitiguem o impacto antrópico ao meio ambiente não está presente apenas nos espaços escolares, esse processo de conscientização também permeia os espaços não escolares.

Nesse sentido, vale ressaltar que, para ambos os espaços, existem respaldos legais para o ensino e aprendizagem da Educação Ambiental. A Política Nacional de Educação Ambiental/PNEA foi implantada no Brasil em 1999, quando as discussões sobre os impactos ambientais foram evidenciadas no país. Tal amadurecimento dos debates sobre o Meio Ambiente trouxe a preocupação em se discutir de forma institucional essa temática sendo ela introduzida como componente urgente e essencial da educação básica, técnica e superior. O Art. 1ำ da Lei Federal $n^{\circ} 9.795$ de 27 de abril de 1999: 
Entende-se por Educação Ambiental os processos por meio dos quais o indivíduo e a coletividade constroem valores sociais, conhecimentos, habilidades, atitudes e competências voltadas para a conservação do meio ambiente, bem de uso comum do povo, essencial à sadia qualidade de vida e da sua sustentabilidade (BRASIL, 1999).

Esse processo de construção individual e coletiva sobre o pensar o Meio Ambiente já estava previsto por meio da Lei 9394/96 de Diretrizes e Bases da Educação Nacional, que instrui que "os currículos do ensino fundamental e médio devem incluir os princípios da proteção e defesa civil e a Educação Ambiental de forma integrada aos conteúdos obrigatórios" (BRASIL 1996). É uma temática transversal a todos os componentes curriculares.

A Política Nacional e Educação Ambiental compreende a importância do ensino e das práticas da EA, que ultrapassem o espaço escolar, indo ao encontro da sociedade como um todo. Neste sentido, reconhecemos o valor desta lei que correlaciona à necessidade de aprender Educação Ambiental em todos os espaços de aprendizagem seja ele formal ou não formal.

Neste sentido, ressaltamos que a Lei Federal n 9.795, em seu Art. 20: "a Educação Ambiental é um componente essencial e permanente da educação nacional, devendo estar presente, de forma articulada, em todos os níveis e modalidades do processo educativo, em caráter formal e não formal" (BRASIL, 1999).

A Lei Federal $n^{\circ} 9.795$ evidencia como o processo do ensino e aprendizagem da EA deve se estabelecer nos espaços não formais em seu Art. 13으:

Entendem-se por Educação Ambiental não formal as ações e práticas educativas voltadas à sensibilização da coletividade sobre as questões ambientais e à sua organização e participação na defesa da qualidade do meio ambiente (BRASIL, 1999).

O aprendizado contínuo da Educação Ambiental permite uma reflexão constante sobre os hábitos do indivíduo, fazendo-o entender o porquê e as consequências ambientais das suas atitudes, tornando-se um cidadão mais sensível e consciente, seja o aprendizado formal ou não formal.

Os termos "não escolar" e "não formal" têm sido utilizados por autores que desejam investigar locais de produção de conhecimento e de ensino e aprendizagem que "trabalham com divulgação científica [...] espaços diferentes da escola, onde é possível desenvolver atividades educativas." (JACOBUCCI, 2000 p. 55). Segundo a autora, os espaços não formais são divididos em espaços institucionais que possuem uma equipe técnica responsável pelo funcionamento (Museus, Jardins Botânicos, Zoológicos, Planetários, entre outros). E os espaços não institucionalizados, ou seja, locais urbanos ou rurais 
que não possuem uma estruturação institucional, mas onde é possível exercer os processos de ensino e aprendizagem (teatro, parque, casa, rua, praça, terreno, cinema, praia, entre outros).

Ambientes artísticos são espaços não formais podendo ser institucionalizados (museus, zoológico, planetários) ou não (teatros, cinema, escolas de artes, entre outros). Sendo espaços de produção e divulgação da arte que provocam nos indivíduos questionamentos em relação aos seus atos frente ao percurso cultural e científico da sociedade (GOHN, 2006; GOMES, NAKAYAMA, 2017; FREITAS, GONÇALVES, 2018). Isso ocorre através da apreciação dos elementos expostos, do relacionamento interpessoal, bem como na relação desses indivíduos com o meio em que vivem. Tais elementos demonstram que esses espaços não escolares são locais de ensino e aprendizagem de diversas temáticas, inclusive sobre Educação Ambiental.

No espaço artístico, não escolar, se "aprende no mundo da vida, via os processos de compartilhamento de experiências, principalmente em espaços e ações coletivas cotidianas" (GOHN, 2006, p. 28). O espaço não escolar tenciona uma prática educativa cuja "experiência destaca a voluntariedade de participação, a inexistência de avaliação, de aquisição de conteúdo e a indefinição de um público organizado por faixa etária ou nível de aprendizagem" (OLIVEIRA; MOURA, 2005, p. 47). Tal pluralidade enriquece as discussões e trocas de conhecimento, pois envolve indivíduos que buscam espaços formativos para conhecer e debater sobre assuntos em que possuam interesse. Além disso, "prolongam os tempos e os espaços de formação e autoformação, com base em necessidades contextuais dos sujeitos e das comunidades, atuando como mecanismo catalisador da articulação de saberes", como afirma Severo (2015, p. 566).

A educação não formal rompe com a hierarquização dos conteúdos e dissolve os currículos existentes da educação formal. Tal 'des'construção faz com que a educação em espaços não formais seja "mais difusa, menos hierárquica e menos burocrática. Os programas de educação não formal não precisam necessariamente seguir um sistema sequencial e hierárquico de 'progressão'” (GADOTTI, 2005, p. 2). Essa constituição dá uma característica própria e peculiar à forma de ensinar e aprender nesses espaços agindo sobretudo "no campo das emoções e sentimentos, atua sobre aspectos subjetivos do grupo e forma a cultura política de um grupo" (FREITAS; BERNARDES, 2013, p. 30085).

Em razão disso, nesses espaços coexistem a sensibilidade, o respeito, a racionalidade e o cuidado, o que favorece a inserção de temas e produções artísticas que evoquem o cuidado ao meio ambiente. Ou seja, a EA, ao ser discutida em diversos espaços, provoca no indivíduo "o conhecimento sob uma ótica de significado para a vida desenvolvendo atitudes e habilidade congruentes para o sentido de aprender [...] Educação Ambiental' (GOMES; NAKAYAMA, 2017, p. 259). 


\section{[...] Mato a esperança do amanhã \\ Em mim \\ Em ti... \\ Oh ser que ainda nem existe. \\ Ou tu que gritas: Extinção! [...]}

\section{Metodologia}

\section{Mudança de cenário}

O estudo aqui apresentado foi desenvolvido no município de Teixeira de Freitas, na escola de artes Agnaldo Bomfim, onde ocorre o projeto de formação de jovens artistas.

O projeto foco da pesquisa teve início no ano de 2017, tendo como objetivo formar jovens como artistas cidadãos que possam, através das diversas expressões da arte, modificar o meio onde vivem, sendo agentes transformadores de si e de outras pessoas. O público-alvo são jovens autônomos ou estudantes do ensino básico ou superior, sendo atualmente cinco integrantes. Destes, duas mulheres, uma estudante universitária a outra concluiu o Ensino Médio (EM); e quatro homens, sendo um o professor e coreógrafo, dois trabalhadores autônomos, ambos com o EM completo, e um que está concluindo um curso técnico em administração. Estes foram selecionados a partir de uma audição pública, cuja inscrição e participação durante todo o curso é voluntária e gratuita.

A escola de artes Agnaldo Bomfim propicia aos seus estudantes a formação básica em diversas áreas artísticas, como dança (ballet, jazz, moderno, contemporânea, urbana, entre outras), teatro e produção artística (figurino, produção cênica).

Essa pesquisa foi baseada em uma perspectiva qualitativa, cujo método de coleta de dados foi pela observação de ações do grupo através das postagens em redes sociais (Facebook e/ou Instagram) e um questionário com os participantes (um professor e cinco cursistas) do projeto de formação artística na cidade de Teixeira de Freitas.

A escolha da realização do questionário ocorreu porque, segundo Gil (2008), a utilização desse instrumento de coleta é conveniente quando o objetivo é entender uma experiência. O questionário é um instrumento de coleta de dados constituído por uma série ordenada de perguntas, que devem ser respondidas por escrito e sem a presença do entrevistador. Além disso, a observação das ações, segundo Gil (2008), é a utilização dos sentidos humanos para a percepção de um determinado fenômeno, examinando assim os comportamentos e hábitos frequentes do público-alvo.

Após a realização dos questionários, as respostas foram analisadas a partir da Análise Textual Discursiva - ATD (MORAES, GALIAZZI, 2006). 
As entrevistas foram sempre precedidas da leitura do Termo de Consentimento Livre e Esclarecido, seguindo as orientações do Comitê de Ética em Pesquisa (CEP-UNEB), aprovado sob o número 3.891.858.

A ATD consiste em uma metodologia de análise de dados que possui três etapas: A unitarização, que busca analisar o texto detalhadamente, subdividindo-o de acordo com as semelhanças relatadas referentes ao(s) fenômeno(s) investigado(s). A fase da categorização, que corresponde à interligação das unidades anteriormente elencadas que começam a ser agrupadas por semelhança, esse processo pode ser a priori, a posteriori ou misto. Com o estabelecimento das categorias, é possível fazer relações com o campo teórico. No âmbito desta pesquisa, foi utilizada a categoria a posteriori, sendo organizada em: 1- Arte e cidadania; 2- Arte e ações socioambientais. Por fim, a terceira etapa vai se construindo, os metatextos, caracterizada por um texto descritivo e interpretativo, pautado no referencial teórico (MORAES; GALIAZZI, 2006). O resultado desta análise permitiu a constituição de dois metatextos; "A dança como espaço de mudança pessoal, social e ambiental" e "Criação e reflexão, atos de mão dupla na arte". Na construção do metatexto, os nomes dos entrevistados e entrevistadas foram substituídos por modalidades de dança, para que suas identidades fossem preservadas, assim como previsto no termo de Livre Esclarecido assinado por todos.

[...] Mato cresça e incomode.

Incomode a indecência

Que te mata todo dia. [...]

\section{Resultados e discussão}

\section{Ato II: A dança como espaço de mudança pessoal, social e ambiental}

A Arte e as suas várias formas de expressão (dança, teatro, música, artes plásticas, literatura, entre outras) derivam de um percurso humano no decorrer de variados períodos, sendo construída em um processo contínuo e mutável. A partir dela, é possível se perceber costumes, valores, expressões corporais e linguísticas de uma sociedade em um determinado período, como afirmam Reis, Guerra e Braga (2006); Freitas e Gonçalves (2018).

Dentre tantas expressões artísticas ensinadas na Agnaldo Bonfim Escola de Dança (ABED), a dança é o cerne principal. Esse campo da arte, a dança, pode ser compreendido por muitos pelo simples movimentar do corpo, no entanto, é a "necessidade corporal de incorporar e desincorporar, de expandir e contrair, de absorver e expelir, e manifesta-se como força/ desejo intrínseco ao corpo vivo, que provoca movimento" (TEIXEIRA; TAVARES, 2020 , p. 99). A dança não se restringe ao movimento, mas abarca uma significação do indivíduo na busca por compreender mais sobre si e sobre o outro numa relação com o ser, ambiente e as transformações sociais. E é nessa perspectiva sociocultural que o grupo de formação da ABED percebe a dança. 
A dança tem um papel fundamental na formação social e humana dos alunos que praticam essa arte. Dançar não é só mexer o corpo, vai além, é disciplina, ética, conhecimentos gerais, o autoconhecimento etc. Faz com que o indivíduo se coloque na sociedade de forma mais consciente. (Ballet)

A dança pode e muito exercer uma importância social, sim, abrindo as mentes das crianças e jovens para um mundo melhor, tirando-as da criminalidade, aumentando a autoestima e o conhecimento pessoal. (Moderno)

A dança é de suma importância no âmbito social, pois é a partir dela que se pode transpassar "regras de convívio", como maior interação entre as pessoas, o respeito ao próximo, dentre outras coisas. (Flamenca)

A dança não mexe só com o corpo, também com a mente, pois ela lida com percepções, sobre o que é bom e o que você faz, para não prejudicar outras pessoas e um pouco mais de noção das coisas ao nosso redor. (Strong)

A dança, segundo os participantes da ABED, possui a questão motriz do corpo, mas também permite aos indivíduos envolvidos nela a oportunidade de romper com a vulnerabilidade social; permite a convivência com pessoas com histórias de vida diferentes, levando ao respeito ao próximo e ao seu percurso de vida; ao autoconhecimento, elevando a autoestima; bem como, a adquirir uma postura social questionando sobre o cotidiano e levando, através da arte da dança, seus ideais.

A dança não ensina só movimentos e estilo de dança, ensina também a se preocupar com o ar que nós respiramos, com a comida, com o lixo, e outras coisas. (Street)

Ao pensarmos em dança, podemos imaginar uma vida de certa forma saudável, e é a partir disto que vamos iniciar a valorização do ambiente (natureza) a nossa volta, como, por exemplo, os elementos nas nossas refeições. (Flamenca)

A dança é uma libertação da mente e corpo. O trabalho consciente da dança contemporânea, por exemplo, nos faz pensar, refletir e buscar ser um ser melhor com atitudes no nosso dia a dia em contato com o mundo. (Moderno)

Quando discutimos em sala de aula sobre o que poderíamos fazer para tornarmos a nossa cidade mais limpa. Assim a poluição não agride tanto a natureza que resta na cidade. $O$ espetáculo "Enlevo", por exemplo, fala sobre o corte das árvores. (Ballet) 
Devido aos trabalhos que fazemos em ambientes diferentes, sobre temas que já trabalhamos para conscientizar as pessoas para ter cuidado com a natureza. (Jazz)

Nas falas acima, nota-se que na ABED, além das modalidades de dança, existe uma preocupação por se fazer uma arte crítica que instiga os seus participantes a pensarem não apenas no seu corpo, como o centro da dança, mas a pensar de maneira socioambiental. Nesse processo, existe um envolvimento da dimensão racional e sensível do humano e, dentre outros aspectos, permite a inserção do indivíduo no mundo com "qualidade social, justamente na compreensão sensível das múltiplas questões (social, econômica, política, ambiental, ética, etc.), que se afiguram na atual sociedade, em intenso processo de transformação" (FREITAS; GONÇALVES, 2018, p. 202).

Nessa constituição da dança a partir de uma visão social e ambiental, muitos aspectos atitudinais são perceptíveis, como o cuidado ambiental no cotidiano quanto à redução na produção de lixo e o cuidado com o ar atmosférico, mas também com o cuidado pessoal quando ressaltada a preocupação por uma alimentação saudável. Essa relação indivíduo e ambiente é percebida também nos trabalhos artísticos do grupo, como ressaltado por Ballet, quando cita o espetáculo "Enlevo". Ou seja, no convívio dentro da instituição de dança, outros aspectos cotidianos e ambientais são discutidos. Nesse espaço não formal, existe o enriquecimento do significado de ensinar e aprender, por meio da integração de diversas áreas do saber, seja a arte ou a Educação Ambiental, sendo "capaz de romper a divisão das disciplinas, contribuindo na formação do cidadão crítico e reflexivo" (FREITAS; BERNADES, 2013, p. 85).

Tais rupturas conceituais não ficam apenas no campo das ideias, elas são percebidas na prática cotidiana, quando há mudança de hábito, sendo um processo de ensino que envolve a ação e a reflexão.

Antes da dança, da formação, tinha práticas que não eram muito boas para o meio ambiente e aqui peguei outras práticas. (Strong)

A dança em si nos ensina a nos tornarmos pessoas melhores, pessoas disciplinadas, pontuais, comprometidos com o meio ambiente, amando o próximo e amando o nosso planeta. (Moderno)

Percebo que meus alunos reconhecem a importância da preservação e de não poluir. Assim levarão para outros ambientes essa importância de cuidar do planeta. (Ballet) 
Devido a nós trabalharmos com a cultura e a conscientização das pessoas, acabamos aderindo às práticas no nosso cotidiano, de ter cuidado com o ambiente em que vivemos para que ele dure mais. (Jazz)

A aprendizagem se constitui na mudança de percepção e, quando as práticas cotidianas se modificam, existe assim uma apreensão e ressignificação das ideias e ações. Nesse processo, eles "reconhecem que as ciências e as artes se encontram e se fertilizam contínua e reiteradamente" (IANNI, 2004, p. 11).

A partir dos relatos feitos, são perceptíveis pelos próprios sujeitos a mudança das suas práticas cotidianas quanto ao meio ambiente, a partir das discussões desenvolvidas durante as atividades junto a ABED. Além da mudança pessoal, existe a preocupação de se propagar essas práticas socioambientais mais conscientes, voltadas à preservação da natureza através de ações individuais e coletivas.

\author{
[...] Mato...Floresça! \\ Em consciências petrificadas. \\ Em uma sociedade fissurada. [...]
}

\title{
Ato III: Criação e reflexão, atos de mão dupla na arte
}

O processo criativo, na arte, engloba o racional (ideias, críticas, descobertas) e o imagético (metáforas, sinestesia, lúdico) para instigar uma reflexão. Entendendo que a reflexão gerará uma ação de mudança, e essa poderá estimular no outro uma transformação formando um elo de hábitos diferentes. Segundo Canda, "ao criar resoluções cênicas para expressar algo, o participante do evento [...] entra em contato com o seu repertório cultural e procura dar uma forma expressiva para determinado conteúdo" (CANDA, 2010, p. 249).

Partindo dessa compreensão, foi proposto que cada discente e o professor descrevessem um espetáculo imaginário, com as palavras chaves; Cidadania; Meio ambiente; Práticas socioambientais. Dos seis entrevistados, cinco aceitaram o desafio.

\author{
Um pequeno mundo (Strong) \\ Há quem diga! (Flamenca) \\ Todo dia (Moderno) \\ Enlevo (Ballet) \\ Todos em prol do mundo (Jazz)
}


Cidadãos com consciência ambiental, cidadãos sem consciência ambiental, mãe natureza, natureza. (Strong)

Mulher, negra, idosa, com conhecimento vasto e narradora; crianças, inteligentes, unidas e alegres; caçadores, sérios e ferozes; animais coloridos, frágeis e sagazes. (Flamenca)

O empresário, a falta de cuidado com o meio ambiente; a mãe, faz de tudo para o filho ser uma grande pessoa; o filho, segue o conselho da mãe, mas trabalha para a empresa; o estudante universitário, que sabe que o mundo pode ser melhor; a sombra, faz os personagens de deslocarem da luz; a luz, os personagens seguem suas boas práticas. (Moderno)

Árvores, seres lindos e que fazem o seu papel de forma eficaz no bioma em que se situa; homem (empresário madeireiro) ganancioso e focado a construir riquezas cada vez maiores. (Ballet)

Em quatro dos espetáculos existe uma polaridade entre os personagens, há aqueles que agridem ao meio ambiente (cidadãos sem consciência ambiental; caçadores; empresários) e os que protegem ou buscam ter atitudes voltadas à preservação (cidadãos com consciência ambiental; mulher negra e idosa, a mãe, o filho). Trata-se de uma construção voltada para BEM $\times$ MAL, PRESERVAÇÃO x DEGRADAÇÃO, uma vez que a humanidade, ao longo da sua "evolução" socioeconômica, foi "perdendo a noção de sua integração com o meio ambiente, adquirindo uma consciência mais individualista" (KONDRAT; MACIEL, 2013, p. 825). No entanto, Jazz faz outra construção de seus personagens:

Mundo, em forma de pessoa (o mundo tem o poder de fazer tanto bem quanto mal às pessoas que o poluírem); árvore, amiga e conselheira (poder de aconselhar e ajudar o mundo); humanos, poder de poluir ou ajudar o mundo (Jazz).

A partir dessa construção, percebe-se uma relação amálgama entre PRESERVAÇÃO/DEGRADAÇẪO nos seus personagens. Jazz, na sua construção, não dicotomiza essas ações, mas as tornas comuns ao ser humano, discutindo o poder da escolha. Nessa perspectiva, Jazz faz uma crítica aos "modelos de consumo vivenciados pelas sociedades, ou pela análise do modo de relação dominadora do ser humano sobre a natureza, com alto valor antropocêntrico" (SATO, 2001, p. 14). Desta forma, evidencia que o ser humano deve se posicionar sendo responsável por suas ações cotidianas ecologicamente corretas ou não.

Quando questionados sobre o cenário dos espetáculos, a antítese espacial também se fez presente em dois relatos: 
Uma floresta sendo engolida pelos arranha-céus. (Strong) Palco dividido ao meio, metade floresta e metade cidade. (Jazz)

A ideia cenográfica, assim como a ideia dos personagens, baseia-se na dicotomia URBANO/NATUREZA CONTEMPLATIVA, sendo que a floresta representa a PRESEVAÇÃO e a cidade, a DEGRADAÇÃO. No entanto, em três cenários, existe a ideia sinérgica de que a humanidade deve preservar o ambiente independentemente de onde esteja.

Climas brasileiros, principalmente o sertão nordestino. (Flamenca)

Uma linda e verde floresta. (Ballet)

Um escritório que muda para casa, que muda para a vida que os estudantes e trabalhadores precisam enfrentar durante o dia a dia até o seu destino. Fundo preto. (Moderno)

Entre os cenários apresentados, Moderno constrói o seu a partir dos diferentes espaços de convivência do ser urbano. Ao problematizar o espaço de preservação, através do cenário, ele mostra com isso que o pensar ecologicamente não está ligado apenas quando o ser humano está em contato com a natureza esteticamente vislumbrada (florestas, cachoeiras), mas se faz no ambiente em que se vive, seja ele urbano ou rural.

Essa visão de preservação focada apenas em datas ou ambientes contemplacionistas é criticada por Sato (2001), quando a autora ressalta que o ambientalismo não se resume a datas comemorativas, mas configura-se em um projeto de vida, através de lutas sociais em prol de cuidados ecológicos necessários para a construção da sociedade ecologicamente consciente.

Apesar de 0 antagonismo estar presente na elaboração dos personagens e no cenário, em grande parte das propostas dos espetáculos, existe a intenção dos autores de discutir temas voltados à degradação do meio ambiente, seja este urbano ou rural. Os entrevistados citam consequências voltadas ao âmbito local e mundial quando as ações cotidianas não buscam mitigar a degradação ambiental.

Quando os humanos começam a sofrer as consequências dos poderes que o mundo tem de fazer mal (aquecimento global, seca etc.). (Jazz)

Do início ao fim. Em todos os momentos. (Ballet)

Em todo momento, no espetáculo, terá uma preocupação com a poluição, meio de transporte, o consumo, as ruas da cidade, até os rios, mares e florestas. Sendo o empresário ambicioso não se importando com o meio ambiente. (Moderno) 
Os autores buscam discutir temáticas relevantes à discussão ambiental, como: aquecimento global, seca, poluição, meio de transporte, consumo, entre outros. Mostra-se dessa forma que a discussão não se centrará apenas na dicotomia PRESERVAÇÃO/DEGRADAÇÃO, de maneira superficial e alegórica. Reverbera-se, ao longo do espetáculo, o que Kondrat e Maciel (2013) afirmam que, ao adotarmos maneiras de desenvolvimento um tanto insustentáveis, relacionadas ao esgotamento de recursos ambientais, à poluição e ao contínuo processo de degradação ambiental, o colapso será inevitável.

Nas narrativas elaboradas pelos discentes do curso de formação de artistas e o professor, é evidente que eles se posicionam sobre temas pertinentes a discussão ambiental, tanto no locus regional quanto mundial. Para Praia, Gil Pérez e Vilches (2007), a compreensão do agir ecologicamente é uma decisão que deve fundamentar as ações dos cidadãos, para tal, não cabe um nível de conhecimentos muito elevado, mas a vinculação das suas vivências locais com a proporção global. Ou seja, o agir ecologicamente não deve ser algo estanque, mas gradual e correlacionada, pois "a sociedade não necessita apenas de consciência, ela precisa também de práticas que ajudem a solucionar os diversos problemas do mundo" (KONDRAT; MACIEL, 2013, p. 826).

\section{[...] Mato... Multiplique-se! \\ Fecunde.}

Até o mato se tornar um ato

De resistência do eu com você.

Naturalizando!

\section{Considerações Finais}

\section{Fecham as cortinas}

Ao discutir Educação Ambiental, é necessário colocar no palco as áreas sociais, econômicas, culturais, científicas e ambientais, pois, a partir delas, reflexões vão sendo constituídas e mudanças serão vivenciadas a cada geração. Nesse artigo, buscamos evidenciar o quanto a arte pode ser esse palco de construção de uma cidadania socioambiental e consciente.

Ao analisar os questionários dos integrantes do projeto de formação artística em Teixeira de Freitas, é evidente que o espaço não formal é um local de discussão sobre as questões ambientais. Tal espaço busca proporcionar a reflexão para tomadas de decisões mais responsáveis com o meio ambiente, através das atividades desenvolvidas pelos envolvidos no projeto.

No decorrer da pesquisa, os participantes do projeto evidenciaram, através das suas falas, o interesse e cuidado em discutir questões ambientais presentes em seu cotidiano em nível local e global. Ao discutirem esses aspectos do micro ao macro em relação à Educação Ambiental, percebe-se que nesse projeto a EA tem sido debatida como forma de enfrentamento e 
propõe aos seus integrantes a reflexão quanto às suas atitudes, bem como, o cuidado em discutir sobre esses temas sociedade/natureza em suas obras.

O presente artigo, ao longo das suas discussões, mostrou que o projeto de formação de jovens artistas tem, através da arte, sido uma ferramenta de construção de uma visão socioambiental e cidadã. Educação Ambiental se faz em todos os locais (formais e não formais), desde que haja a preocupação com uma atitude consciente frente à natureza.

Pretendemos, com este artigo, reverberar que ensinar, aprender e refletir sobre Educação Ambiental faz-se no cotidiano, pois o tempo de aprender e escolher praticar ações socioambientais conscientes se faz no tempo presente, para que gerações possam ter o direito e dever de desfrutar e também preservar o meio ambiente.

\author{
ATO \\ Mato que cresce teimoso. \\ Ato de resiliência! \\ Mesmo quando ao lado, \\ Tudo sufoca a existência. \\ Mato sempre que abafo, \\ Em mim, o ato de cuidado. \\ Entre resíduos e mais resíduos \\ Nasce uma frase... Um slogan: \\ Consumo consciente! \\ Hilário! \\ Icônico! \\ Algo antagônico? \\ Um ar fresco no \\ "eu consumidor". \\ Mato a esperança do amanhã \\ Em mim \\ Em ti... \\ Oh ser que ainda nem existe. \\ Ou tu que gritas: Extinção! \\ Mato cresça e incomode. \\ Incomode a indecência \\ Que te mata todo dia. \\ Mato...Floresça! \\ Em consciências petrificadas. \\ Em uma sociedade fissurada. \\ Mato... Multiplique-se! \\ Fecunde. \\ Até o mato se tornar um ato, \\ De resistência do eu com você, \\ Natureze-se!
}




\section{Agradecimentos}

Aos que participaram desta pesquisa (cursista e professor da Escola de Artes Agnaldo Bomfim de Teixeira de Freitas), pelo tempo e conhecimento concedido ao presente estudo;

\section{Referências}

BRASIL. Lei no 9.394, de 20 de dezembro de 1996. Estabelece as diretrizes e bases da educação nacional. Presidência da República Federativa do Brasil, Brasília, DF, 1996. Disponível em: <http://www.planalto.gov.br/ccivil 03/leis/19795.htm>. Acesso em: 11 maio 2020.

BRASIL. Lei $n^{\circ} 9.795$, de 27 de abril de 1999. Política Nacional de Educação Ambiental, Brasília,DF, abr 1999. Disponivel em: $<$ http://www.planalto.gov.br/CCIVil 03/LEIS/L9795.htm>. Acesso em: 11 set. 2018.

BRASIL. Lei n. 9795, de 27 de abril de 1999. Dispõe sobre a Educação Ambiental, institui a Política Nacional de Educação Ambiental e dá outras providências. Presidência da República Federativa do Brasil, Brasília, DF, 1999. Disponível em: <http://www.planalto.gov.br/ccivil 03/leis/l9795.htm>. Acesso em: 11 maio 2020.

CACHAPUZ, A. F. Arte e ciência no ensino das ciências. Interacções, Portugal, n. 31, p. 95-106, 2014.

CANDA, C. N. Sentidos da arte: diálogos entre teatro, a experiência estética e a educação. Revista Científica da Faculdade de Artes do Paraná, Curitiba, v. 5, p. 243-261, 2010.

CARVALHO, L. M. A temática ambiental e o processo educativo: dimensões e abordagens. In: CINQUETTI, H. C. S.; LOGAREZZI, A. (Org.). Consumo e resíduo: fundamentos para o trabalho educativo. São Carlos: EdUFSCar, p. 18-41, 2006.

DEGASPERI, T. C.; BONOTTO, D. M. B. Educação Ambiental e as dimensões cognitiva e afetiva do trabalho com valores: produzindo sentidos. Ciência Educativa, Bauru, v. 23, n. 3, p. 625-642, 2017.

DOMINGUES, T. C. Educação e cidadania: aspectos legais, concepções e processos pedagógicos desenvolvidos na ETEC de Piedade-SP à luz de Gramsci. 2017. Dissertação (Mestrado em Educação). Programa de Pós-Graduação em Educação da UFSCar, São Paulo.

FREITAS, B.; BERNARDES, M. B. J. Educação Ambiental: Ações Educativas em Espaços Não Formais. Anais do XI Congresso Nacional de Educação, 2013, Curitiba., p. 1-19. Disponível em: <file:///C:/Users/Cliente\%20PC/Downloads/7194 4592.pdf> Acesso em: 23 abr. 2020.

FREITAS, N. M S.; GONÇALVES, T. V. O. Práticas teatrais e o ensino de Ciências: o teatro jornal na abordagem da temática do lixo. Educar em Revista. Curitiba, v. 34, n.68, p. 199-216, mar/abr 2018.

GADOTTI, M. A questão da educação formal/não formal. Disponível em: <file:///C:/Users/Cliente\%20PC/Downloads/A\%20QUEST\%C3\%830\%20DA\%20EDUC A\%C3\%87\%C3\%830\%20FORMAL N\%C3\%830-FORMAL.pdf> . Acesso em: 23 abr. 2020 .

Revista brasileira educação ambiental 
GIL, A. C. Métodos e técnicas de pesquisa social. 6 ed. São Paulo: Atlas, 2008. Disponível

em: $<$ http://www.moodle.ufba.br/file.php/12618/Livro Antonio Carlos Gil.pdf $>$. Acesso em 16 jun. 2018.

GOHN, M. G. Educação não formal, participação da sociedade civil e estruturas colegiadas nas escolas. Ensaio: aval. pol. públ. Educ., Rio de Janeiro, v.14, n.50, p. 27-38, jan./mar. 2006.

GOMES, R. K. S.; NAKAYAMA, L. Educação Ambiental: saberes necessários a práxis educativa docente de uma escola amazônica amapaense. Educar em Revista, Curitiba, n. 66, p. 257-273, out./dez. 2017.

JACOBUCCI, D. F. C. Contribuições dos espaços não-formais de educação para a formação da cultura científica. Em Extensão, v. 7, n. 1, 5 nov. 2008.

KLISYS, A. Ciência, arte e jogo. São Paulo: Peirópolis, 2010.

KONDRAT, H.; MACIEL, M. D. Educação Ambiental para a escola básica: contribuições para o desenvolvimento da cidadania e da sustentabilidade. Revista Brasileira de Educação, v. 18 n. 55, p. 825 -1058, out.-dez. 2013.

MORAES, R; GALIAZZI, M. do C. Análise textual discursiva: processo reconstrutivo de múltiplas faces. Ciência \& Educação. v. 12, n. 1, p. 117-128. 2006.

OLIVEIRA, C. L.; MOURA, D. G. Projetos Trilhos Marinhos - uma abordagem de ambientes não-formais de aprendizagem e metodologia de projetos. Educação e Tecnologia. Belo Horizonte, v.18, n.3, p. 46-61, jul/dez 2005.

PRAIA, J; GIL-PÉREZ D.; VILCHES A. O papel da natureza da ciência na educação para a cidadania. Revista Ciência \& Educação, v. 13, n. 2, p. 141-156, 2007.

REIS, J. C.; GUERRA, A.; BRAGA, M. Ciência e arte: relações improváveis? História, Ciências, Saúde, Manguinhos, Rio de Janeiro, v. 13 (suplemento), p. 71-87, 2006.

RODRIGUES, C. S. A dimensão estética da Educação Ambiental nos entendimentos e práticas de arte educadores e de professores da escola de ensino fundamental. 2009. $66 \mathrm{f}$. Trabalho de conclusão de curso. Universidade Estadual Paulista - Júlio de Mesquita Filho, São Carlos. São Carlos, 2009.

SATO, M. Debatendo os desafios da Educação Ambiental. Revista Eletrônica do Mestrado em Educação Ambiental, Rio Grande: Universidade Federal do Rio Grande; FURG, v. 1, p. 14-33, 2001.

SEVERO, J.L.R.L. Educação não escolar como campo de práticas pedagógicas. Rev. bras. Estud. pedagog. (online), Brasília, v. 96, n. 244, p. 561-576, set./dez. 2015.

TEIXEIRA, C. L; TAVARES, G. M. Corpo de Afetos: entre o apego emocional e o movimento dançado. Fractal: Revista de Psicologia, v. 32, n. 1, p. 99-107, jan.-abr. 2020. 